\title{
Evaluation of Pictures and Graphics Semiotics in National kindergarten Interactive Curriculum in Jordan
}

\author{
Reham M Al-Mohtadi \\ $\mathrm{PhD}$, Department of Curriculum and Teaching \\ School of Education, Al-Hussein Bin Talal University, P.O. Box (20), Ma'an, Jordan \\ E-mail: jordanian81@hotmail.com
}

Mustafa Jwaifell

PhD, Instructional Technology

E-mail: jwaifell@hotmail.com

Intisar Aldarabah

$\mathrm{PhD}$, Early childhood

E-mail: Entesusm@yahoo.com

Received: June 18, 2015 Accepted: August 14, 2015 Published: August 14, 2015

doi:10.5296/jse.v5i3.8003

URL: http://dx.doi.org/10.5296/jse.v5i3.8003

\begin{abstract}
This research aimed at evaluation of pictures and graphics semiotics in national kindergarten interactive curriculum in Jordan. Frequencies of items reflecting semiotics were used to evaluation pictures and graphics included in the Jordanian National Kindergarten Interactive Curriculum (JNKIC), depending on the study instrument which was built for the study's purposes. The study results showed that a rich curriculum in graphics and pictures in addition to that it's high quality content, in addition, the literacy level in the pictures and graphics high quality. On the other hand, there is a clear lack of observance pictures and graphics that care with special needs. The researchers recommended giving more attention in the curriculum included pictures and graphics take into account the special needs, in addition, conducting further studies on the evaluation of interactive curriculum from the teachers view point and its relationship between their experience and qualification.
\end{abstract}

Keywords: Semiotic, Pictures and Graphics, kindergarten 


\section{Introduction}

Pictures are considered a form of expression of a part of reality by the Graphics or pictures which have very important role in the communication field, in addition to language. The picture language may perceived messages more than the spoken languages, for that researchers discussed it as a tool of communication that can be beyond the obvious message to enrich mediation. It can be described as a new field of research, considering it a craftsmanship dominating a large sector of science, cognition, art and entertainment and carries in its folds evidences, meanings and symbols bestow upon it a value and makes it an effective communication tool in the technical, cultural, social, political and economic transformation, achieving by that a communicative, convincing, civilized and aesthetic role (Al-fadli, 2010).

Sandel (1999) indicated that pictures and graphics semiotics are considered important mean in teaching at pre-school stage, while ignoring intellectual activation related pictures leads to linguistic problems rated between (40\%-60\%) that the fact of pictures and graphics semiotics understanding will motivate children attention and perception to what they learn at all subjects fields. Thus, it can be said that the semiotics approach does not stand at just observing, reading and describing pictures, but exceed that to a comprehensive evaluation to determine weakness and strengths in resembling the content as the most important element of the curriculum.

The school books occupy a distinguished position in the field of education, considered as a tool of the curriculum, and a basic axis in the educational work and the basic reference of the student. Mostly, text-books considered the message that the ministry of education stress on, carried out by teachers and stimulated intellectually and behaviorally by the student (Yassin, 2009). The Jordanian National Kindergarten Interactive Curriculum (JNKIC) is considered the primary source, from which children acquire epistemology, thus scholars and academics hold responsibility of examining the curriculum and evaluating them from several sides and approaches to define extent of achieving its aims and objectives.

Both assessing text-books and its content are necessary as much is important for policy makers to make decisions for development curriculums and enhancing what it contains of pictures, graphics and visual aids which occupy a numerous importance in learning and perception. So, it demands analysis and revision to understand the extent of what educational standards those pictures and graphics where designed and created to be perceived correctly by the students, while a lake of studies examined pictures and graphics semiotics, even examining various existing sides of weakness and defect in the educational graphics in many books, and they were not laid in accordance with firm and specific standards (Aasqul, 2002).

\section{Background of the study}

Significant funds have been invested by the ministry of Education in Jordan to develop JNKIC, where scholars give great efforts in analyzing JNKIC with a lake of researches about graphics and pictures semiotics, which may lead to cultural biases stand against community 
believes, do the impotency of messages perceived by the children as receivers, may lead to miss perception.

\subsection{Pictures and Graphics}

Content represents the second of the curriculum elements: Aims, Content, Methodology and Evaluation (ACME). After stating objective, While determining the content is the second element faces curricula planners (sa'adeh, 2001), and the process of evaluating the curriculum with its elements is considered one of most important processes carried out by the educators, where evaluation is the initial procedure of the development process to redirect designing and planning curriculum by elimination weaknesses and strengthen what related directly to the objectives for better implementation.

Despite of these processes importance, the process of evaluating graphics and pictures semantics in text-books did not meet enough concern by scholars, in spite of its importance in kindergarten learning which should begin with concrete to abstract and upon it instruction addresses lean on purpose of convincing the learner and affecting him by establishing a mean of a concrete communication media. It can be said that it is one of the convincing means that reflect incentives in the external world easily and automatically by using the sense of seeing (Al-Saady, 2009).

Picture is an expressive means, and communicative connecting our ancient inherited traditions with our culture, Bruner assured that by the picture; the learner becomes more active and people remember $(10 \%)$ only from what they hear, and $(30 \%)$ of what they read, meanwhile what they remember (80\%) from what they see and do (lester,2000).

Pictures and graphics are the most important components of the (JNKIC) that refers to their assistance of child in explaining knowledge, understanding and what they containing of concepts relations. They also assist to develop the children's imagination and raise the level of their thinking and both inductive and conductive thinking. Besides that, pictures and graphics work as a tool of increasing the children's culture and it can hasten their learning process of things and related names, especially that the process of reading pictures demands from the child to perform mental operation characterized with depth. It can be said, that there is a relationship between the memory operations and employing pictures and illustrative graphics, especially in both operations; recalling in and remembering (Al-Shanti, 2011).

No doubt that pictures and graphics considered as picturing symbols of what it indicate to as a clear indication while experiments proved that they assist in understanding words and forming sentences by the lowest possible translation, and so assists the teacher to solve the problem of distant place and time of learners in a language understood by all learners, regardless their cultural and educational level (El-Faouri and Abu-Awad, 2012).

Owing to the overspread of the picture in the world by its different excellences, analyzing them became an important in research fields, and also the transformation of semiotic curriculum as a successful tool needed to uncover its evidences, because semiotics came to shortage the gap between humanities sciences and experimental sciences and pausing the embedded meanings of pictures (Thani,2008), where pictures semiotic analysis assists in 
interrogating the aesthetic elements in it to reach its depth evidences that exceed its both apparent attraction and prettiness, and so reaching what those evidences mean, either in the religious, cultural, or national dimension beside the economic domain as a creative outcome submissive to privacies of the environment.

\subsection{Semiotic}

Bengrad (2003) defines semiotics as a study of the living marks inside the social life, pointing to uncover and explore indicative invisible relations through the direct excellence of reality, and it is a training of the eye on picking the implied, hidden, and preventing, and not pure satisfaction with nominating zones or expressing the components of the content. Mean while Thani (2008) defined it as a science of indicative indication, whatever was its type and origin, for the system of the universe with all it contains of indications and symbols is a system with evidence, and semiotics is specialized with structures of these indications, their distribution and their internal and external functions; for semiotics searches for the meaning through the structure of difference, language of the form and the indicative structure. It is so doesn't concern about the text and who said it, but it attempts to answer one question: how did the picture say what it said? For that the picture is dismantling and reassembled to define its structural constants.

Bilaabed (2007) indicates that receiving the picture is being summarized at the first stage, for the eye wipes the picture, but its spreads on the same frame, and not by the writing how which we receive/read the text, but this complete reading does not stay in to become in a second stage a writing reading, because our sight concentration on the picture will not provide us with all message and possible indications all at once. So, the eye required to perform a group of vertical, horizontal, and circular movements, specifying by that the track of the picture.

Lowe (2000) assured that the skill of reading the pictures and graphics must not be confined to student of a stage than the other, but must be available amongst student at all studying stage, starting from the school, kindergarten, and the university, and the skills of reading the pictures and explanatory drawings became from the important objective, which must be available amongst learners, and the learners in the early level from the elementary education must be able to look at the pictures and explanatory graphics and reading beyond them. Mean while Shoules (1982) views that the educational value of semiotic appears in training the reader to read the visual (picture) text deeply, and so recognizing the deep meanings, by that there is an aware generation, discerning, difficult to influence them. Also there is a training of the correct logical thinking built on the existence of introductions and results, and a development of the creative thinking because the semiotic analysis of any picture differs from a person and another, and from a zone to another, and from time to another. Also there is in it a conscious study of the facts, the ongoing incidents. The semiotic must be studied in light of reality and within its social context.

Marks or indications in Semiology may be words or pictures from which meanings can be derived, and this curriculum was implied in analyzing films and also in other fields connected with communication and information. For the semiotic analysis is considered a new language, 
for dealing with the television material, or cinema is done as well as dealing with language on the basis of relations importance that connect among its parts, and not on the basis of being these relations pure things do not indicate to a thing (Suleiman, 2004).

\subsection{Previous studies}

Studies were done about the importance of the social background in understanding pictures and evaluating them. Callow's study (2003) explored students' understanding of the visual aspects of their own multimedia presentations. Investigating the nature of students' understanding of visual texts is an important area of research in the "new illiteracies." The research suggests that students need access to a metalanguage in order both to explain their own visual designs and to develop more sophisticated and critical understandings about how visual texts in general are constructed. For this to occur, teachers require an understanding of visual features, as well as the ability to incorporate appropriate pedagogical practices into the classroom environment.

Meanwhile Mahmoud study (2007) aimed at proposing a suggested strategy in developing motivating revelation and creative spaces through pictures semiotics. The study tried to investigate the relationship between graphics contained in Arabic Language text book, with each of objectives and content beside its importance, suitability, reality, clarity, components and elements quantity. The study deduced the necessity of concern about the picture and its context visual systems in curricula and giving it important concern in the university level from part of its nature, types and its importance for the learners.

Teachers have significance in evaluating pictures and graphics provided in school books. The study conducted by Abu Ammar (2012) aimed at investigating teachers point views in both basic grades; the first and the second in the extent of employing standards of designing graphics and pictures for both sides; the technical and instructional purpose, in accordance with type of scientific qualification and teaching experience, and the studying class they teach, and analyzing graphics and pictures in the text book of "Arabic is my language" to recognize the extent of achieving both operations of educational performing design, aestheticism in the form of graphics and pictures and their content. The study sample consisted of teacher of both basic grades; the first and the second at schools of Damascus governorate, sample where (264) male and female teachers in the year (2011-2012). Also (185) Picture and graphic were chosen from the whole graphic and educational pictures in text book "My-book Arabic is my language". The result indicated that graphics and pictures in "My-book Arabic is my language" had achieved a very good level of employing of designing standards of pictures and graphics from the point of view of teachers of both basic grades; the first and second and with approaching percentages of both technical and educational sides.

\section{Purpose of the study}

While JNKIC was one of the basic elements in the learning teaching process of the kindergarten stage in Jordan, which is witnessing its first steps in implementation, this study aimed at evaluating pictures and graphics semiotics of JNIC to explore the weakness and strengthens of the JNKIC by answering the following questions: 


\section{Ml Macrothink}

1-What is the extent of achieving both functions of instructional performance designing and the aesthetical performance in JNKIC according to the graphics and pictures measurement analyses tool?

2-What are the graphics and pictures semiotics included in the JNKIC?

\subsection{Population of study}

The study population was represented in books of the JNKIC in Jordan used in year (2014-2015), which consisted of three books (two books of Arabic language activities, mathematics, and a book of English language activities). The pictures and graphics contained in JNKIC are shown in Table 1:

Table 1. Pictures and Graphics in each unit in the JNKIC

\begin{tabular}{llcc}
\hline Unit & Unit name & Number of pictures & Book / Part \\
\hline First & My Kindergarten and I & 46 & Part one of the Book, \\
Second & My Family & 27 & Arabic language and \\
Third & My Animals & 30 & Mathematics \\
\hline Fourth & National & 28 & Part Two of the Book, \\
Fifth & My Plants & 23 & Arabic language and \\
Sixth & My Water & 26 & Mathematics \\
Seventh & My Land & 24 & Chapter one and two \\
\hline English language Book ( Full Book) & Total & 230 & \\
\hline \multicolumn{5}{l}{}
\end{tabular}

Out of Table 1 the JNKIC includes (203) pictures and graphics distributed on seven units. It is obvious that the first unit has (46) pictures and graphics resembling (17\%) of the pictures and graphics in total.

\section{Methodology and Tools of study}

The study used the analytical approach to identify availability of the function of both instructional and aesthetical performance design throughout the repetition of the indications of the items that represent the whole semiotics of the pictures and graphics. The measurement tool of the study consisted of three parts to evaluate pictures and graphics:

1. Pictures and graphics instructional performance design. This part consisted of (20) item reflecting the function of pictures and graphics according to its instructional performance design.

2. Pictures and graphics aesthetical performance design. The second part consisted of (20) item reflecting the function of pictures and graphics according to its aesthetical performance design. 


\section{Macrothink}

3. Pictures and graphics semiotics, which consisted of (40) items distributed equally into four domains: Social semiotics, Economical semiotics, National semiotics and Religious semiotics.

Validity was extracted by academic referees in al-Hussein Bin Talal University, specialized in kindergartens and instructional technology, while reliability calculated by evaluating a unit randomly chosen from units of the JNKIC by the researcher, who is specialized in kindergartens and a female teacher of kindergartens using of (Holsti) equation for the reliability of analysis through counting the points of agreement among analyzers on the total of points of the first analyzer and points of these second analyzer, and the unit had included (30) Pictures and Graphics from (230) Pictures and Graphics, included by the JNKIC at a rate of $(23 \%)$ from the total of Pictures. The tool scale graduated in agree $=$ availability and disagreed $=$ not available to judge the availability of the items.

\section{Results of study and discussions}

The researchers analyzed the pictures and graphics included in JNKIC according to the three parts of the measurement tool. Frequencies of agreements of researchers' analyses for each picture or graphic are organized according to the study questions:

Question One: What is the extent of achieving both functions of instructional performance designing and the aesthetical performance in JNKIC according to the graphics and pictures measurement analyses tool?

To answer the first question, frequencies on agreement of evaluating according to the tool scale were calculated for all the (230) picture and graphics contained in JNKIC. This question is divided into two parts; the first one is about the pictures and graphics function of instructional performance design, while the second one is about the pictures and graphics function of aesthetical performance design.

First: Instructional performance design .Table 2 showing results of analyses for each item under this domain: 
Table 2. Frequencies of Pictures and Graphics Instructional Performance Design

\begin{tabular}{|c|c|c|c|c|}
\hline No & Standard & Frequencies & $\begin{array}{l}\text { Rank at the } \\
\text { domain }\end{array}$ & $\begin{array}{l}\text { Rank at } \\
\text { the total }\end{array}$ \\
\hline 1 & Related to children previous experiences. & 225 & 7 & 23 \\
\hline 2 & Assists learner to build knowledge. & 227 & 2 & 13 \\
\hline 3 & Treats daily life social problems. & 224 & 11 & 31 \\
\hline 4 & Related to learning objectives. & 227 & 2 & 13 \\
\hline 5 & Motivates questions to ask. & 220 & 19 & 47 \\
\hline 6 & Grows national and nationalistic feeling. & 225 & 7 & 23 \\
\hline 7 & Stirs students' learning motivation. & 221 & 18 & 45 \\
\hline 8 & Motivates value respect and positive attitudes. & 225 & 7 & 23 \\
\hline 9 & $\begin{array}{l}\text { Copes with students' mental and psychological } \\
\text { characteristics of the age category directed to } \\
\text { them. }\end{array}$ & 222 & 16 & 43 \\
\hline 10 & Concentrates on the content main concepts. & 224 & 11 & 31 \\
\hline 11 & Provide spatial concepts. & 222 & 16 & 43 \\
\hline 12 & Provide time concepts. & 224 & 11 & 31 \\
\hline 13 & $\begin{array}{l}\text { Motivates students' ability of observation, } \\
\text { analysis and critical thinking. }\end{array}$ & 225 & 7 & 23 \\
\hline 14 & Providing several types of images. & 226 & 5 & 20 \\
\hline 15 & Clear message that related to the objectives. & 195 & 20 & 55 \\
\hline 16 & $\begin{array}{l}\text { Enriching the text by with new visual } \\
\text { experiences. }\end{array}$ & 227 & 2 & 13 \\
\hline 17 & $\begin{array}{l}\text { Provoking non-typicality in thinking and } \\
\text { performance. }\end{array}$ & 223 & 14 & 40 \\
\hline 18 & Considerate individual differences. & 229 & 1 & 4 \\
\hline 19 & Related to learners environment. & 223 & 14 & 40 \\
\hline 20 & $\begin{array}{l}\text { Questions accompanying the pictures measure } \\
\text { recognition, description, and explanation. }\end{array}$ & 226 & 5 & 20 \\
\hline \multicolumn{2}{|c|}{ Total } & 4460 & & 1 \\
\hline
\end{tabular}

Out of Table 2: it appears that graphics and pictures achieved function of instructional performance design in JNKIC with (4460) frequency out of the total frequency throughout graphics and pictures $=230$ multiplied by the $20^{\text {th }}$ items under this domain $(230 * 20=4600)$ with $97 \%$ percentage. While the domain ranked=1. Item 18) Considerate individual differences where ranked $=1$ at this domain and 4 at the total, while items 15) Clear message that related to the objective where ranked $=19$ at the domain and ranked $=47$ at the total and 5) Motivates questions to ask where ranked $=20$ at the domain and ranked $=55$ at the total are still achieving both functions of instructional performance designing in JNKIC. 


\section{Macrothink}

Journal of Studies in Education

ISSN 2162-6952

2015, Vol. 5, No. 3

Second: Aesthetical performance design .Table 2 showing results of analyses for each item under this domain:

To answer the second part of the first question, frequencies on agreement of evaluating according to the tool scale were calculated for all the (230) picture and graphics contained in JNKIC. The following Table showing the pictures and graphics function of aesthetical performance design frequencies of the evaluation tool:

Table 3. Frequencies of Pictures and Graphics technical aesthetic Performance Design

\begin{tabular}{|c|c|c|c|c|}
\hline No & Standard & Frequencies & $\begin{array}{c}\text { Rank at } \\
\text { the } \\
\text { domain }\end{array}$ & $\begin{array}{l}\text { Rank at } \\
\text { the total }\end{array}$ \\
\hline 21 & Attracting attention. & 208 & 16 & 54 \\
\hline 22 & Clarity. & 191 & 18 & 57 \\
\hline 23 & Reality in its elements. & 175 & 20 & 59 \\
\hline 24 & Emotional and dramatic impact. & 223 & 8 & 40 \\
\hline 25 & Affected by foreign books elements. & 224 & 5 & 31 \\
\hline 26 & Submitting various concepts about time & 226 & 3 & 20 \\
\hline 27 & $\begin{array}{l}\text { Accuracy in delivering expression language such } \\
\text { as gestures and body language. }\end{array}$ & 216 & 13 & 51 \\
\hline 28 & $\begin{array}{l}\text { Submitting logically correct concepts about } \\
\text { pro-rata. }\end{array}$ & 219 & 12 & 50 \\
\hline 29 & Avoiding random and mess in graphic and design. & 186 & 19 & 58 \\
\hline 30 & $\begin{array}{l}\text { Embodiment of the third dimension at the level of } \\
\text { line and color. }\end{array}$ & 225 & 4 & 23 \\
\hline 31 & Appropriate use of light and shadow. & 224 & 5 & 31 \\
\hline 32 & $\begin{array}{l}\text { Variety in the techniques of technical designing } \\
\text { and finishing. }\end{array}$ & 227 & 1 & 13 \\
\hline 33 & Enriching visual traditional and heritage concepts. & 220 & 10 & 47 \\
\hline 34 & Picturing local environments & 220 & 10 & 47 \\
\hline 35 & Employing colors usefully. & 199 & 17 & 55 \\
\hline 36 & Enriching creative experiences. & 227 & 1 & 13 \\
\hline 37 & Appropriateness design for learners. & 214 & 15 & 53 \\
\hline 37 & Full with action. & 216 & 13 & 51 \\
\hline 39 & Simplicity without many details. & 224 & 5 & 31 \\
\hline 40 & Appropriates dimensions to paper size. & 221 & 9 & 45 \\
\hline \multicolumn{2}{|r|}{ Total } & 4285 & & 3 \\
\hline
\end{tabular}

Out of Table 3: it appears that graphics and pictures achieved technical aesthetic performance design in JNKIC with (4285) frequency out of the total frequency throughout graphics and pictures $=230$ multiplied by the $20^{\text {th }}$ items under this domain $(230 * 20=4600)$ with $93 \%$ 


\section{Macrothink}

Journal of Studies in Education

ISSN 2162-6952 2015, Vol. 5, No. 3

percentage. While the domain ranked=3, Items 32) Variety in the techniques of technical designing and finishing, And 36) Enriching creative experiences, where ranked $=1$ at this domain and 13 at the total, while item 23) Reality in its elements, where ranked=19 at the domain and ranked=59 at the total and. the total is still achieving technical aesthetic performance design in JNKIC.

\section{Question Two: What are the graphics and pictures semiotics included in the JNKIC?}

To answer the second question of the study, frequencies of the three analyzers' agreement was counted for each item and sub domain as shown in Table 4: 
Table 4. Frequencies of Pictures and Graphics Semiotics

\begin{tabular}{|c|c|c|c|c|c|}
\hline $\begin{array}{c}\text { Sub } \\
\text { domain }\end{array}$ & No & Standard & Frequencies & $\begin{array}{l}\text { Rank at } \\
\text { the } \\
\text { domain }\end{array}$ & $\begin{array}{c}\text { Rank at } \\
\text { the } \\
\text { total }\end{array}$ \\
\hline \multirow{5}{*}{ 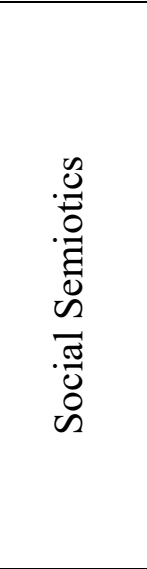 } & 41 & $\begin{array}{l}\text { Concentration on the different categories } \\
\text { of the community such as special needs. }\end{array}$ & 1 & 20 & 60 \\
\hline & 42 & Loving others and lending them a hand & 229 & 4 & 4 \\
\hline & 43 & Altruism & 225 & 14 & 23 \\
\hline & 44 & $\begin{array}{l}\text { Importance of social relations among } \\
\text { families. }\end{array}$ & 227 & 12 & 13 \\
\hline & 45 & $\begin{array}{l}\text { Maintain social skills concerning the } \\
\text { value of cooperation and loving others } \\
\text { and reflections on the individual of } \\
\text { community }\end{array}$ & 229 & 4 & 4 \\
\hline \multicolumn{3}{|r|}{ Total } & 911 & & \\
\hline \multirow{6}{*}{ 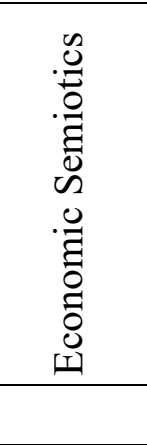 } & 46 & Rationalization of consumption & 225 & 14 & 23 \\
\hline & 47 & Support of national production & 228 & 8 & 10 \\
\hline & 48 & Concentration on the tourist locations & 224 & 17 & 31 \\
\hline & 49 & Preventing monopolization & 229 & 4 & 4 \\
\hline & 50 & $\begin{array}{l}\text { Concentration on rising the national } \\
\text { currency }\end{array}$ & 228 & 8 & 10 \\
\hline & & Total & 1134 & & \\
\hline \multirow{5}{*}{ 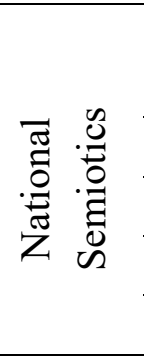 } & 51 & $\begin{array}{l}\text { Concentration on the citizenship identity } \\
\text { and affiliation. ( language and religion ) }\end{array}$ & 224 & 17 & 31 \\
\hline & 52 & Desire to show the national customs & 229 & 4 & 4 \\
\hline & 53 & Showing the figure of the flag. & 230 & 1 & 1 \\
\hline & 54 & Recognizing the Jordan map. & 230 & 11 & 1 \\
\hline & 55 & Safeguarding holy places & 230 & 1 & 1 \\
\hline \multicolumn{3}{|r|}{ Total } & 1143 & & \\
\hline \multirow{5}{*}{ 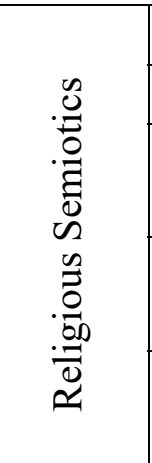 } & 56 & Concentration on The Holy Qur'an & 229 & 4 & 4 \\
\hline & 57 & Desire to show the Islamic modest clothes & 227 & 12 & 13 \\
\hline & 58 & $\begin{array}{l}\text { The Islamic Feasts and what connected to } \\
\text { (fasting of Pilgrimage). }\end{array}$ & 225 & 14 & 23 \\
\hline & 59 & $\begin{array}{l}\text { Concentration on thanking God before } \\
\text { and after having meals }\end{array}$ & 224 & 17 & 31 \\
\hline & 60 & $\begin{array}{l}\text { Sympathize with the young people and } \\
\text { respecting old people }\end{array}$ & 228 & 8 & 10 \\
\hline \multicolumn{3}{|r|}{ Total } & 1133 & & \\
\hline \multicolumn{3}{|r|}{ Semiotics Total } & 4321 & & 2 \\
\hline
\end{tabular}


It is clear from the previous table that Item 41) Concentration on the different categories of the community such as special needs, had the lowest rank in this domain, where it got the rate of (20), mean while, the highest rank were Items: 53) Showing the figure of the flag and 55) Safeguarding holy places had the highest ranking under this domain and in total.

Also, it appears that semiotics of graphics and pictures are still pointing effectively without any cultural biases, so it can be said that graphics and pictures under each of its domains (Social, Economic, National and Religious semiotics are employed in an effective way in the JNKIC.

\section{Conclusion}

The research revealed that pictures and graphics in JKIC are well selected for the kindergarten stage, while some of these pictures are a way of dealing with those who have special needs. The researchers' recommendations focusing of conducting further studies on the evaluation of interactive curriculum from the teachers view point and its relationship between their experience and qualification.

\section{References}

Abu Ammar, Nisrreen. (2012). Employing Educational Pictures and Graphics in books of "Arabic is my language" for First and Second Graders, Analytic. (Master Thesis). University of Damascus. Syria.

Alasqul, Mohammed Abdelfattah. (2002). Evaluation Of Illustrations in the 1st Grade Science Book - Elementary Education, Journal Humanities Research. Islamic University $\begin{array}{llllll}\text { Journal, } & 10, & \text { (2). } & \text { Pp. } & 45-70 . & \text { [Online] }\end{array}$ http://resportal.iugaza.edu.ps/articles/volume10-\%20Issue2\%20Human\%202.pdf

Al-Fadhli, Sadiyyah. (2010). Image Culture and Role in Enriching Aesthetic Appreciation of Viewers. (Master Thesis). Um Al-Qura university, Saudi Arabia.

Al-Saady, Ahmad. (2009). Picture in School's Text-Book, Manner and Function- Partial Educational center. Morocco.

Ash-shanti, Afaf. (2011). The Agreement Between Picture and World Culture as A criterion for Quality in The Content of Palestinian Science Book With its First \& Second Parts for The Fourth Graders. (Master Thesis). Al -Azhar University, Gaza, Palestine.

Bilaabid, AbdelHag. (2007). Image Semiotic, Between the Machineries of Reading and Qonquests of Interpretation. Philadelphia Twelfth International conference, culture of Image. (24-26) April. [Online] Available http://www.philadelphia.edu.jo/arts/12th/abstract1.htm\#_Toc269884983 (July 7, 2013).

Bingrad, Said. (2003). Semiotics: Concepts and Applications. Al-Zaman publications. cazablanca, Morocco. 


\section{Macrothink}

Callow, J. (2003). Talking about Visual Texts with Students. [Online] Available: http://www.readingonline.org/articles/art_index.asp?HREF=callow/index.html (October, 7, 2014)

El-Faouri, Awni, \& Abu-Awad, Inas (2012). Impact of Using Image in Teaching Arabic Language to Speakers of Other Languages in The University of Jordan. Human and Social Sciences, 39(2), 275-284.

Lester, Paul. Martin. (2000). Visual Communication: Images with Messages, London: Wadsworth.

Lowe Richard, (2000). Visual Literacy in Science and Technology EducationUNESCO International Science, Technology \& Environmental Education Newsletter. [Online] Available: http://unesdoc.unesco.org/images/0014/001462/146292e.pdf

Mahmoud, Hasan (2007). The Picture Semiotics" a Suggested Strategy in Developing Motivating Revelation and Creative Spaces, Philadelphia Twelfth International conference, culture of [Online] Available http://www.philadelphia.edu.jo/arts/12th/abstract1.htm\#_Toc269884983. (April, 8, 2014).

Sa'adeh, Jawdat \& Ibrahim, Abdullah. (2001). Curriculum Organizations, Planning and Development. Amman: Ashorouk Publishers, Amman, Jordan.

Sandel, Pueschel. (1999). the Special Child, Paulh. Brookes public Merryland, British Library.

Shoules, Robert (1982). Semiotics and Interpretation. Yale University Press. Translated by Saed Al-ghanmi (1994). Arab association for studies and Publication.

Suleiman, Ibrahim Mohammad (2014). Introduction to the Concept of Picture Inspiration. (16th) The Center of Research \& Scientific Consulatansity. University Bulletin. (2. Pp.153-178, University of Zawia.

Thani, Qadour (2008). Sīmayā'īyat al-șūrah: mughāmarah sīmayā'īyah fī ashhar al-irsālīyāt al-bașarīyah fī al-‘ālam, Al-Warraq for publication \& distribution, Amman, Jordan.

Yassin, Salah. (2009). Assessment of Curriculums: a sharing in the discussion about the Palestinian curriculums. Ro'a Tarbawiah, AM Qattan Foundation, Ramallah..30.Pp.131Online]

Available:http://www.qattanfoundation.org/sites/default/files/u2/roaa_30_2009-11_020.pdf 